\title{
INTRAVENOUS CO-INFUSION OF ADENOSINE AND NOREPINEPHRINE PRECONDITIONS THE HEART WITHOUT ADVERSE HEMODYNAMIC EFFECTS
}

Michael V. Cohen, MD

Jon D. Thornton, MD, PhD

Christy S. Thornton, MD

Hiroshi Sato, PhD

Takayuki Miki, MD

James M. Downey, $\mathrm{PhD}$
Objective: A simple intervention is needed that could protect the heart against infarction during limited-access coronary artery bypass grafting. Adenosine and norepinephrine can precondition the heart with resulting protection, but adverse hemodynamic effects prevent clinical application. Because heart rate, blood pressure, and contractility effects of these two drugs are diametrically opposite, a mixture might be beneficial. Methods: A superficial branch of the left coronary artery of rabbits was surrounded with a suture. Infarction was produced in all hearts by a 30-minute coronary artery occlusion. Infarct size after reperfusion was measured and is presented as a percentage of the risk zone. The effect of 5 -minute intravenous co-infusion of adenosine $(20 \mathrm{mg} / \mathrm{kg})$ and norepinephrine $(0.1$ $\mathrm{mg} / \mathrm{kg}$ ) 15 minutes before ischemia was examined. In addition, the protective effect of three sequential intravenous bolus injections of adenosine at either 0.2 or $0.4 \mathrm{mg} / \mathrm{kg}$ was evaluated. Results: Thirty minutes of regional ischemia caused infarction of $40 \% \pm 4 \%$ of the risk zone. The combination of adenosine and norepinephrine caused no change in blood pressure but rather protected the heart, with infarction of only $9 \% \pm 2 \%$ of the risk zone ( $p=0.0001$ vs control). Adenosine-norepinephrine co-infusion still protected the heart when the interval between infusion and ischemia was extended to 60 minutes, but it did not protect with a 120 -minute interval. Intravenous bolus injections of adenosine resulted in cardiac slowing and marked hypotension. Boluses of $0.2 \mathrm{mg} / \mathrm{kg}$ resulted in a minimal, but significant, reduction in infarct size, whereas the higher dose provided no protection. Conclusion: Adenosine-norepinephrine co-infusion provides a feasible and safe parenteral method for preconditioning the heart. (J Thorac Cardiovasc Surg 1997;114:236-42)
Lis imited-access myocardial revascularization ${ }^{1}$ is increasing in popularity because of diminished postoperative discomfort and complications and reduced hospital stays. Unfortunately, traditional methods of myocardial preservation with cardioplegia cannot be used in these patients because the

From the Departments of Medicine and Physiology, University of South Alabama College of Medicine, Mobile, Ala.

Supported in part by grants from the National Institutes of Health: Heart, Lung, and Blood Institute grants HL-20648 and HL-50688.

Received for publication Dec. 16, 1996; revisions requested Feb. 14, 1997; revisions received March 11, 1997; accepted for publication March 13, 1997.

Address for reprints: Michael V. Cohen, MD, Department of Physiology, MSB 3050, University of South Alabama, College of Medicine, Mobile, AL 36688.

Copyright (C) 1997 by Mosby-Year Book, Inc.

$0022-5223 / 97 \$ 5.00+0 \quad \mathbf{1 2} / \mathbf{1} / \mathbf{8 1 9 4 7}$ heart is maintained in a normothermic and beating state. An alternative method of cardiac protection might be preconditioning with either ischemia or pharmacologic agents. Ischemic preconditioning has received much attention since its initial description in 1986 by Murry and associates. ${ }^{2}$ Paradoxically, brief episodes of ischemia enable the myocardium to better withstand a subsequent period of ischemia, resulting in a marked resistance against infarction. In addition to reduced infarction, preconditioning may also improve recovery of postischemic ventricular function ${ }^{3}$ and diminish the incidence of malignant ventricular arrhythmias both during ischemia and after reperfusion., ${ }^{4,5}$

The mechanism of this protection has been eagerly sought. In rats $^{6}$ and rabbits, ${ }^{7}$ protein kinase C activation appears to be critical to the protection. Furthermore, in the rabbit agonists to any of the cardiac receptors that are coupled to protein kinase 
$\mathrm{C}$, including the adenosine $\mathrm{A}_{1},{ }^{8}$ the $\alpha_{1}$-adrenergic, ${ }^{8}$ the bradykinin $\mathrm{B}_{2}{ }^{8}$ the angiotensin II $\mathrm{AT}_{1},{ }^{8}$ the muscarinic $\mathrm{M}_{2},{ }^{9}$ the endothelin ET- $1,{ }^{10}$ and the opioid $\delta$ or $\kappa^{11}$ receptors, can trigger protection in lieu of brief ischemia. Interestingly, in the rat an opioid $^{12}$ rather than adenosine ${ }^{13}$ appears to be the principal trigger.

Previously reported successful ischemic preconditioning before coronary revascularization has involved brief periods of aortic crossclamping before more prolonged intervals of ischemic arrest. ${ }^{14}$ However, this technique is not possible during limitedaccess surgery. Although brief occlusions of the isolated left anterior descending coronary artery could be used to precondition a portion of the myocardium, it would be better to pharmacologically protect the myocardium in a global fashion before any manipulation of the coronary artery. Unfortunately, all of the known pharmacologic triggers of preconditioning ${ }^{7,15,16}$ cause either unacceptable hypotension (adenosine, carbachol, and bradykinin) or hypertension ( $\alpha_{1}$-agonists, angiotensin II, and endothelin-1), are carcinogenic (phorbol esters), or induce serious pulmonary disease (sodium oleate). Although intracoronary bradykinin might be capable of preconditioning the heart with minimal adverse hemodynamic effects, ${ }^{17}$ the requirement for selective infusion into a coronary artery to minimize the amount of drug reaching the peripheral vasculature limits the usefulness of this approach.

Although both adenosine ${ }^{18}$ and norepinephrine $^{19,20}$ can trigger protection, they have opposite effects on heart rate, contractility, and blood pressure. The object of this study was to see whether we could induce protection by co-infusion of these two agents into a peripheral vein at doses that produced equivalent but opposing effects on hemodynamics. If such a mixture could be achieved, then it might well be possible to precondition the heart of the patient with cardiac disease by means of intravenously administered drugs with minimal hemodynamic side effects.

\section{Methods}

All experiments were performed in accordance with the "Guide for the Care and Use of Laboratory Animals" (National Academy Press, Washington, revised 1996) and were approved by the Institutional Animal Care and Use Committee of the University of South Alabama.

Surgical procedures. New Zealand White rabbits of either sex, weighing between 1.4 and $3.5 \mathrm{~kg}$, were anesthetized with intravenous sodium pentobarbital $(30 \mathrm{mg} /$ $\mathrm{kg}$ ). The trachea was intubated through a cervical incision, and the animals' lungs were mechanically ventilated with a positive-pressure respirator (MD Industries) and $100 \%$ oxygen with an initial tidal volume of $15 \mathrm{ml}$ and a rate of $30 \mathrm{breaths} / \mathrm{min}$. The respiratory rate was adjusted to keep blood $\mathrm{pH}$ in the physiologic range. Body temperature was maintained near $38^{\circ} \mathrm{C}$ with a heating pad. A carotid artery and jugular vein were cannulated for blood pressure monitoring and additional anesthesia and drug administration, respectively. A left thoracotomy was performed in the fourth intercostal space, and the pericardium was opened to expose the heart. A 2-0 silk suture on a curved taper needle was passed around a prominent branch of the left coronary artery, and the ends were pulled through a small vinyl tube to form a snare. The coronary branch was occluded by pulling the snare, and myocardial ischemia was confirmed by the appearance of regional cyanosis. Reperfusion was achieved by releasing the snare and was documented by visible hyperemia of the surface of the heart.

Infarct size measurement. At the end of the experiment hearts were quickly excised, mounted on a Langendorff apparatus, and perfused at room temperature with saline solution for 1 minute to wash out blood. The coronary artery was then reoccluded, and 1 to $10 \mu \mathrm{m}$ zinc cadmium sulfide fluorescent particles (Duke Scientific) were infused to demarcate the risk zone as the nonfluorescent region. The heart was weighed, frozen, and then cut into transverse slices approximately $2 \mathrm{~mm}$ thick. The slices were thawed and stained by incubation for 20 minutes at $37^{\circ} \mathrm{C}$ in $1 \%$ triphenyltetrazolium chloride in $\mathrm{pH} 7.4$ buffer. The areas of infarct (tetrazolium negative) and risk zone (nonfluorescent under ultraviolet light) were determined by planimetry. Infarct and risk zone volumes were then calculated by multiplying each area by the slice thickness and summing the products. Infarct size was expressed as a percentage of the risk zone infarcted.

Protocols. All rabbits were subjected to 30 minutes of regional ischemia followed by 180 minutes of reperfusion. A control group of rabbits was subjected only to this ischemia-reperfusion sequence. In the second group of rabbits (NE group), norepinephrine, $0.1 \mathrm{mg} / \mathrm{kg}$, was infused over 5 minutes starting 15 minutes before the 30-minute ischemic insult. Co-infusion of norepinephrine, $0.1 \mathrm{mg} / \mathrm{kg}$, and adenosine, $20 \mathrm{mg} / \mathrm{kg}$, was performed in the third group (NE-ADO group). This dose of adenosine was determined to be one that countered the hypertensive effect of the adrenergic agonist. These two agents were co-infused over 5 minutes, and administration ceased 10 minutes before the long coronary occlusion. So that we could determine how long the combined norepinephrine and adenosine effect persisted, the drug-free interval between the 5-minute drug infusion and the 30-minute coronary occlusion was lengthened first to 60 minutes (NE+ADO-60) and then 120 minutes (NE+ADO-120) in two additional groups of rabbits.

Two other groups of rabbits were studied. In one group, three sequential intravenous boluses of adenosine, $0.2 \mathrm{mg} / \mathrm{kg}$, were administered before the $30-$ minute coronary occlusion; in the second group, the dose of adenosine was doubled to $0.4 \mathrm{mg} / \mathrm{kg}$. After each injection, a 5-minute recovery period was permitted 
Table I. Effect of norepinephrine and adenosine on heart rate and blood pressure

\begin{tabular}{|c|c|c|c|c|c|c|c|c|c|c|}
\hline & \multicolumn{2}{|c|}{ Baseline } & \multicolumn{2}{|c|}{ Drug(s) } & \multicolumn{2}{|c|}{30 min after drug(s) } & \multicolumn{2}{|c|}{ Occlusion } & \multicolumn{2}{|c|}{ Reperfusion } \\
\hline & $\begin{array}{c}H R \\
\text { (beats/min) }\end{array}$ & $\begin{array}{c}M A P \\
(m m H g)\end{array}$ & $\begin{array}{c}H r \\
\text { (beats/min) }\end{array}$ & $\begin{array}{c}M A P \\
(m m H g)\end{array}$ & $\begin{array}{c}H R \\
\text { (beats/min) }\end{array}$ & $\begin{array}{c}M A P \\
(m m H g)\end{array}$ & $\begin{array}{c}H R \\
\text { (beats/min) }\end{array}$ & $\begin{array}{c}M A P \\
(m m H g)\end{array}$ & $\begin{array}{c}H R \\
\text { (beats/min) }\end{array}$ & $\begin{array}{c}M A P \\
(m m H g)\end{array}$ \\
\hline & & & 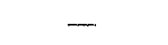 & - & 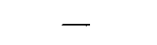 & 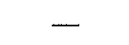 & & & & \\
\hline $\mathrm{NE}$ & & 59. & $6 \pm 10.3$ & 115.8 & - & - & & & & \\
\hline $\mathrm{NE}+\mathrm{ADO}$ & $239.6 \pm 13.3$ & $69.2 \pm 5.0$ & $203.9 \pm 8.4 \uparrow$ & $9 \pm 7.2$ & - & - & 247.6 & 56.0 & 246.1 & 60.7 \\
\hline $\mathrm{NE}+\mathrm{ADO}-60$ & $241.1 \pm 12.2$ & $56.1 \pm 3.1$ & $224.1 \pm 8.9 \dagger$ & $51.2 \pm 2.1$ & $239.9 \pm 11.7$ & $59.5 \pm 3.5$ & $234.1 \pm 17.4$ & $51.6 \pm 2.5$ & $258.3 \pm 29.5$ & $57.4 \pm 3.3$ \\
\hline $\mathrm{NE}+\mathrm{ADO}-120$ & $261.2 \pm 7.7$ & $56.2 \pm 4.1$ & $243.5 \pm 11.0 \dagger$ & $54.2 \pm 2.6$ & $271.2 \pm 13.0$ & $58.7 \pm 3.5$ & $250.0 \pm 20.4$ & $52.0 \pm 1.5$ & $244.8 \pm 11.9$ & $47.6 \pm 3.2$ \\
\hline
\end{tabular}

Values are mean \pm standard error of the mean. Measurements were made at the end of the drug infusion, after 30 minutes of coronary occlusion, and after 60 minutes of reperfusion. $A D O$, Adenosine; $A D O-60,120,60$ - and 120-minute drug-free interval between end of drug infusion and onset of 30-minute coronary occlusion; $H R$ heart rate; $M A P$, mean arterial pressure; $N E$, norepinephrine. Statistical significance of difference between experimental observation and baseline: ${ }^{*} p<0.001 ; \uparrow p<0.01$.

Table II. Effect of intravenous boluses of adenosine on heart rate and blood pressure

\begin{tabular}{|c|c|c|c|c|c|c|c|c|}
\hline & \multicolumn{2}{|c|}{ Baseline } & \multicolumn{2}{|c|}{ Drug } & \multicolumn{2}{|c|}{ Occlusion } & \multicolumn{2}{|c|}{ Reperfusion } \\
\hline & $\begin{array}{c}H R \\
\text { (beats/min) }\end{array}$ & $\begin{array}{c}M A P \\
(m m \mathrm{Hg})\end{array}$ & $\begin{array}{c}H R \\
\text { (beatsimin) }\end{array}$ & $\begin{array}{c}M A P \\
(m m H g)\end{array}$ & $\begin{array}{c}H R \\
\text { (beats/min) }\end{array}$ & $\begin{array}{c}M A P \\
(m m H g)\end{array}$ & $\begin{array}{c}H R \\
\text { (beats/min) }\end{array}$ & $\begin{array}{c}M A P \\
(m m H g)\end{array}$ \\
\hline Control & $264.8 \pm 12.7$ & $86.9 \pm 5.0$ & - & - & $260.6 \pm 12.8$ & $75.3 \pm 5.0$ & $266.0 \pm 17.0$ & $73.3 \pm 4.5$ \\
\hline ADO-0.2 & $251.3 \pm 5.4$ & $71.2 \pm 4.0$ & $220.7 \pm 5.2^{*}$ & $41.5 \pm 3.1^{*}$ & $243.9 \pm 7.3$ & $62.3 \pm 3.4 \dagger$ & $240.4 \pm 8.3$ & $63.0 \pm 3.2$ \\
\hline $\mathrm{ADO}-0.4$ & $244.0 \pm 8.5$ & $78.2 \pm 4.6$ & $208.7 \pm 11.2 \ddagger$ & $41.2 \pm 1.4^{*}$ & $246.3 \pm 9.0$ & $68.7 \pm 3.9 \S$ & $235.7 \pm 10.5$ & $52.9 \pm 3.9 \S$ \\
\hline
\end{tabular}

Values are mean \pm standard error of the mean. Peak drug effects were measured. Other measurements were made at the end of the 30-minute coronary occlusion and after 60 minutes of reperfusion. For abbreviations see Table I. Statistical significance of difference between observation and baseline: ${ }^{*} p<$ $0.005 ;$; $p<0.05$. Statistical significance of difference between control and treatment groups: $\nmid p<0.001 ; \S p<0.05$.

before the next injection. Five minutes after administration of the third bolus, the coronary artery was occluded as detailed earlier.

Statistics. All data are presented as mean \pm standard error of the mean. One-way analysis of variance combined with Tukey's post-hoc test was used to test for differences in infarct size between groups. Analysis of variance with replication was used to test for differences in hemodynamics in any given group. When a significant group difference was detected, observations at individual time points were compared with paired $t$ tests by means of a Dunn-Sidàk correction for multiple comparisons.

\section{Results}

Thirty-seven rabbits were successfully prepared for the protocols designed to evaluate the efficacy of co-infusion of norepinephrine and adenosine. As demonstrated in Table I, hemodynamics before treatment were comparable in all groups. Intravenous norepinephrine significantly raised mean arterial blood pressure from 59.8 to $115.8 \mathrm{~mm} \mathrm{Hg}(p=$ 0.0003 ). This doubling of pressure was not accompanied by any significant change in heart rate. Co-infusion of this same dose of norepinephrine and adenosine caused no significant change in blood pressure ( 69.2 to $62.9 \mathrm{~mm} \mathrm{Hg}, p=0.83$ ), but it did have a small bradycardic effect $(p=0.04)$. Similar changes were observed in the NE+ADO-60 and NE+ADO-120 groups. All hemodynamic changes regressed quickly after discontinuation of the infusions. Hemodynamics were not significantly altered during coronary occlusion and subsequent reperfusion. Blood pressure was lowest at the termination of the 3-hour reperfusion period in the NE+ADO-120 rabbits, probably because those preparations were evaluated for 1 to 2 hours longer than the others.

Twenty-five rabbits were successfully prepared for study of the effects of sequential intravenous bolus injections of adenosine, including a second control group. Baseline heart rates presented in Table II for these three groups were similar to those reported in Table I, whereas blood pressures were modestly higher. Blood pressure declined after each bolus of adenosine by an average of 30 to $35 \mathrm{~mm} \mathrm{Hg}$, and heart rate decreased by 30 to 40 beats $/ \mathrm{min}$. Changes were similar in the lowand high-dose groups. Hemodynamics always returned to baseline levels within 2 minutes and, therefore, before the next bolus injection or the coronary occlusion.

Infarct data from the first five groups of hearts are presented in Table III and Fig. 1. Heart weight and risk zone sizes did not differ significantly among the groups. The risk zone for the NE+ADO-120 rabbits tended to be smaller, but the difference was not 


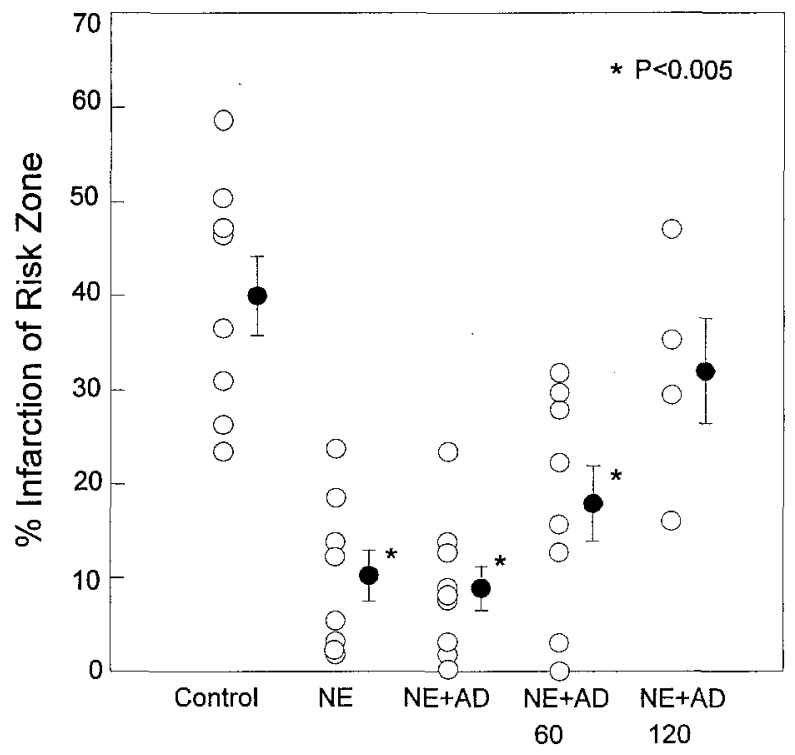

Fig. 1. Infarct size normalized as percent infarction of the risk zone. Open symbols indicate individual experiments and solid symbols indicate the group means and standard error of the mean. Note that protection is beginning to wane 60 minutes after treatment with a combination of norepinephrine $(N E)$ and adenosine $(A D)$ and is completely absent 120 minutes after treatment.

significant ( $p$ ranged from 0.12 to 0.57 for comparisons with the other four groups). Infarction averaged $40.0 \% \pm 4.2 \%$ of the risk zone in control animals. A 5-minute infusion of norepinephrine alone decreased infarct size to $10.2 \% \pm 2.7 \%(p=$ $0.0001)$. Salvage was similar in rabbits treated with both norepinephrine and adenosine (infarct size $8.9 \% \pm 2.3 \%$ of risk zone, $p=0.0001$ vs control). As the drug-free interval between termination of the norepinephrine-adenosine infusion and the onset of the 30-minute coronary occlusion increased, protection waned. Some protection remained after a 60minute drug-free interval $(p=0.002)$. However, when the interval was extended to 2 hours, infarction was not different from that observed in control animals $(p=0.72)$. Fig. 2 and Table IV show the infarct data in the rabbits treated with intravenous boluses of adenosine. Although the hearts in the 0.4 $\mathrm{mg} / \mathrm{kg}$ adenosine treatment group were modestly larger than those in the control group, the risk zone volumes were comparable in all three groups. In the control group, infarct size averaged $37.2 \% \pm 2.0 \%$ of the risk zone, similar to that measured in the other control group. With the smaller dose of adenosine, infarction averaged $25.4 \% \pm 3.1 \%$ of the risk

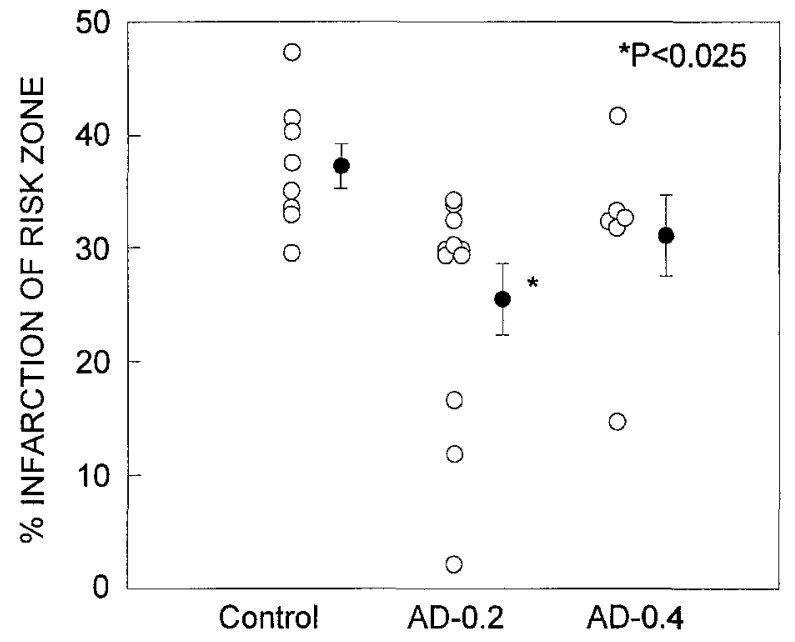

Fig. 2. Infarct size normalized as percent infarction of the risk zone. Open symbols indicate individual experiments and solid symbols indicate the group means and standard error of the mean. Three successive boluses of adenosine ( $A D-0.2), 0.2 \mathrm{mg} / \mathrm{kg}$, produced a very small, but significant, protective effect ( $p<0.025$ vs control). On the other hand, the higher dose $(A D-0.4)$ of $0.4 \mathrm{mg} / \mathrm{kg}$ had no salutary effect.

zone. This infarct size was only minimally less than that observed in untreated rabbits, but the difference was significant $(p=0.02)$. The larger dose of adenosine clearly had no effect on infarct size ( $p=$ 0.72 ).

\section{Discussion}

Ischemic preconditioning can salvage jeopardized myocardium in all experimental animal species tested to date: rat, ${ }^{13}$ rabbit, ${ }^{18}$ pig, ${ }^{21}$ and dog. ${ }^{2}$ Furthermore, isolated human ventricular myocytes can be preconditioned, ${ }^{22}$ and ischemic preconditioning has also been shown to be a clinical phenomenon. ${ }^{14,23-26}$ Preconditioning would be ideal for protection of hearts of patients undergoing limitedaccess myocardial revascularization in which traditional cardioplegic agents cannot be used. However, its use would not be precluded in patients undergoing a midline sternotomy needed for more extensive myocardial revascularization, even when cardioplegia can be used. If a coronary artery must be occluded or flow stopped, myocardial necrosis may develop. The latter may be attenuated with a preconditioning protocol.

As noted earlier, multiple pharmacologic agents can trigger preconditioning in experimental models of myocardial ischemia and infarction, but none has 
Table III. Effect of norepinephrine and adenosine on infarct size

\begin{tabular}{lcccccc}
\hline & $N$ & $\begin{array}{c}B W \\
(\mathrm{~kg})\end{array}$ & $\begin{array}{c}H W \\
(\mathrm{gm})\end{array}$ & $\begin{array}{c}\text { Risk zone } \\
\left(\mathrm{cm}^{3}\right)\end{array}$ & $\begin{array}{c}\text { Infarct } \\
\left(\mathrm{cm}^{3}\right)\end{array}$ & $\begin{array}{c}I / R \\
(\%)\end{array}$ \\
\hline Control & 8 & $2.3 \pm 0.2$ & $7.0 \pm 0.3$ & $0.76 \pm 0.05$ & $0.31 \pm 0.05$ & $40.0 \pm 4.2$ \\
NE & 8 & $1.8 \pm 0.1$ & $6.4 \pm 0.4$ & $0.68 \pm 0.05$ & $0.07 \pm 0.02^{*}$ & $10.2 \pm 2.7^{*}$ \\
NE+ADO & 9 & $2.0 \pm 0.2$ & $7.2 \pm 0.4$ & $0.84 \pm 0.05$ & $0.08 \pm 0.02^{*}$ & $8.9 \pm 2.3^{*}$ \\
NE+ADO-60 & 8 & $2.0 \pm 0.1$ & $6.8 \pm 0.3$ & $0.88 \pm 0.09$ & $0.15 \pm 0.04 \dagger$ & $17.9 \pm 4.0^{*}$ \\
NE+ADO-120 & 4 & $1.8 \pm 0.1$ & $6.8 \pm 0.2$ & $0.57 \pm 0.11$ & $0.18 \pm 0.05$ & $32.0 \pm 5.6$ \\
\hline
\end{tabular}

Values are mean \pm standard error of the mean. For abbreviations see Table I. $B W$, Body weight; $H W$, heart weight; $I / R$, infarct/risk zone ratio; $N$, number of animals. Statistical significance of difference between experimental group and control: ${ }^{*} p<0.005 ; \uparrow p<0.05$.

Table IV. Effect of intravenous boluses of adenosine on infarct size

\begin{tabular}{lrccccc}
\hline & $N$ & $\begin{array}{c}B W \\
(\mathrm{~kg})\end{array}$ & $\begin{array}{c}H W \\
(\mathrm{gm})\end{array}$ & $\begin{array}{c}\text { Risk zone } \\
\left(\mathrm{cm}^{3}\right)\end{array}$ & $\begin{array}{c}\text { Infarct } \\
\left(\mathrm{cm}^{3}\right)\end{array}$ & $\begin{array}{c}I / R \\
(\%)\end{array}$ \\
\hline Control & 8 & $2.0 \pm 0.1$ & $6.7 \pm 0.2$ & $0.97 \pm 0.08$ & $0.37 \pm 0.05$ & $37.2 \pm 2.0$ \\
ADO-0.2 & 11 & $2.3 \pm 0.0^{*}$ & $7.5 \pm 0.4$ & $0.89 \pm 0.07$ & $0.23 \pm 0.03$ & $25.4 \pm 3.1 \dagger$ \\
ADO-0.4 & 6 & $2.2 \pm 0.1$ & $8.2 \pm 0.4 \ddagger$ & $1.06 \pm 0.10$ & $0.35 \pm 0.06$ & $31.0 \pm 3.6$ \\
\hline
\end{tabular}

Values are mean \pm standard error of the mean. For abbreviations see Tables I and III. Statistical significance of difference between experimental group and control: ${ }^{*} p<0.005 ; \nmid p<0.025 ; \ddagger p<0.05$.

been considered for clinical use because of unacceptable side effects. Adenosine is the prototypical preconditioning agonist. Its endogenous production by ischemic myocytes is considered to be the major trigger of ischemic preconditioning. ${ }^{15}$ Although exogenous adenosine $(1.4 \mathrm{mg})$ can trigger protection and significantly diminish infarct size in the isolated rabbit heart in which peripheral hemodynamic effects are absent, an intravenous infusion of $5 \mathrm{mg}$ delivered over 5 minutes reduced blood pressure from 94 to $51 \mathrm{~mm} \mathrm{Hg}$ in in situ hearts and failed to protect them. ${ }^{18}$ In the present experiments, we found that boluses of adenosine induced modest bradycardia and often severe hypotension. Because only the lower dose resulted in minimal, but significant, protection, it is uncertain whether the latter was related to the exogenously infused adenosine. In some animals the adenosine decreased the blood pressure to less than $30 \mathrm{~mm} \mathrm{Hg}$, and this fall may have been sufficient to induce enough myocardial ischemia to trigger the preconditioning phenomenon. The range of infarct sizes in this group, as depicted in Fig. 2, suggests that only three of the 11 hearts showed some evidence of protection, again implying that a factor additional to the exogenously administered adenosine may well have been operational. Endogenous $\alpha_{1}$-adrenergic stimulation does not play a physiologic role in ischemic preconditioning in the rabbit, ${ }^{19,27}$ but phenylephrine, ${ }^{27}$ norepinephrine released by tyramine administration, ${ }^{19}$ and exogenous norepinephrine ${ }^{20}$ are all capable of triggering protection. Intravenously administered $\alpha_{1}$ - agonists, however, produce peripheral arteriolar vasoconstriction with unacceptable hypertension.

Because of the largely opposing hemodynamic effects of adrenergic and adenosine agonists, we hypothesized that a combination of the two might be capable of triggering cardioprotection while having little net hemodynamic effect. In the present experiments the norepinephrine-adenosine cocktail salvaged ischemic myocardium to an extent comparable with that seen with norepinephrine alone $e^{19,20}$ or after brief episodes of ischemia. ${ }^{18}$ Blood pressure was unaffected, however, and the bradycardic effect was small. Like ischemic preconditioning, the protection persisted long after the infusion was discontinued. Protection only partially waned if coronary occlusion was delayed for 60 minutes after cessation of drug infusion, and it disappeared if 2 hours elapsed between infusion and occlusion. This time course matches that already reported for ischemic preconditioning. ${ }^{28}$ Although the drug cocktail successfully diminished infarction, neither effects on arrhythmias nor myocardial stunning could be evaluated with this rabbit infarct model.

Currently several techniques are in use to slow or stop the heart at critical times during the revascularization procedure when only limited access is available. Cooley ${ }^{1}$ uses a rapid-acting $\beta$-blocker, and some surgeons administer adenosine boluses with doses comparable with those used in our rabbits. The bolus of $0.2 \mathrm{mg} / \mathrm{kg}$ would be comparable with administration of $14 \mathrm{mg}$ to a $70 \mathrm{~kg}$ man, a dose typically used for the treatment of supraventricular 
tachycardia. Adenosine administered in this fashion had obvious $A_{2}$ and modest $A_{1}$ effects. Although intravenous adenosine may be successful at decreasing heart rate, our data suggest that this regimen probably does not reliably precondition the in situ heart.

Both adenosine $\mathrm{e}^{18}$ and norepinephrine ${ }^{19}$ can trigger the preconditioned state. It is not clear what the relative contribution of either was in this study. In pilot studies we found that rabbits would not survive the adenosine dose of $20 \mathrm{mg} / \mathrm{kg}$ used in the present investigation when infused alone; thus we cannot determine whether sufficient adenosine receptor stimulation would have occurred to precondition the heart in the absence of the norepinephrine. The animals did survive the norepinephrine infusion and were protected. This result would suggest that sufficient norepinephrine was present to precondition the heart without need for a second agent. This is not surprising, because both norepinephrine and adenosine are thought to precondition the heart by activating protein kinase $\mathrm{C}^{8}$ Thus in this situation in which norepinephrine has already activated enough protein kinase $\mathrm{C}$ to protect the heart, concomitant administration of adenosine would be expected to have little additional effect. Because of the marked hemodynamic effect of the norepinephrine, we cannot exclude the possibility that the norepinephrine infusion actually caused the release of endogenous adenosine that could have contributed to the protection. ${ }^{29,30}$ Whatever the case, the combination of the two agonists was sufficient to trigger the preconditioned state.

In this study we chose norepinephrine as the $\alpha_{1}$-agonist rather than a more selective agent such as phenylephrine. ${ }^{27}$ It was considered desirable to have an agent with some $\beta_{1}$ activity to counter the negative chronotropic and inotropic effects of adenosine. As a result, heart rate changes were attenuated with a small net bradycardia. Substitution of phenylephrine for norepinephrine might slow the heart further, which could provide an additional technical benefit during surgery.

The norepinephrine-adenosine cocktail should be well tolerated. Both agents are produced by the intact organism and, therefore, the risk of unknown and undesirable long-term effects is remote. We know of no adverse consequences of acute administration. The main advantage of the cocktail is that it can be infused intravenously and, if complications do develop, the infusion can be easily discontinued. Both agents have very short durations of action. We suggest that such a combination of agents could prove very useful for triggering of preconditioning in settings in which iatrogenic ischemia is planned or is unavoidable, as in limited-access coronary bypass operations.

The technical assistance of W. Keyser Impastato is gratefully acknowledged.

\section{REFERENCES}

1. Cooley DA. Limited access myocardial revascularization: a preliminary report. Tex Heart Inst J 1996;23:81-4.

2. Murry CE, Jennings RB, Reimer KA. Preconditioning with ischemia: a delay of lethal cell injury in ischemic myocardium. Circulation 1986;74:1124-36.

3. Asimakis GK, Inners-McBride K, Medellin G, Conti VR. Ischemic preconditioning attenuates acidosis and postischemic dysfunction in isolated rat heart. Am J Physiol 1992;263: H887-94.

4. Shiki K, Hearse DJ. Preconditioning of ischemic myocardium: reperfusion-induced arrhythmias. Am J Physiol 1987; 253:H1470-6.

5. Vegh A, Papp JG, Parratt J. Attenuation of the antiarrhythmic effects of ischaemic preconditioning by blockade of bradykinin $B_{2}$ receptors. Br J Pharmacol 1994;113:116772.

6. Mitchell MB, Meng X, Ao L, Brown JM, Harken AH, Banerjee A. Preconditioning of isolated rat heart is mediated by protein kinase C. Circ Res 1995;76:73-81.

7. Ytrehus K, Liu Y, Downey JM. Preconditioning protects ischemic rabbit heart by protein kinase $\mathrm{C}$ activation. Am J Physiol 1994;266:H1145-52.

8. Cohen MV, Downey JM. Myocardial preconditioning promises to be a novel approach to the treatment of ischemic heart disease. Annu Rev Med 1996;47:21-9.

9. Hendrikx M, Toshima Y, Mubagwa K, Flameng W. Muscarinic receptor stimulation by carbachol improves functional recovery in isolated, blood perfused rabbit heart. Cardiovasc Res 1993;27:980-9.

10. Wang P, Gallagher KP, Downey JM, Cohen MV. Pretreatment with endothelin-1 mimics ischemic preconditioning against infarction in isolated rabbit heart. J Mol Cell Cardiol 1996;28:579-88.

11. Chien GL, Van Winkle DM. Naloxone blockade of myocardial ischemic preconditioning is stereoselective. $\mathrm{J}$ Mol Cell Cardiol 1996;28:1895-900.

12. Schultz JEJ, Rose E, Yao Z, Gross GJ. Evidence for involvement of opioid receptors in ischemic preconditioning in rat hearts. Am J Physiol 1995;268:H2157-61.

13. Li Y, Kloner RA. The cardioprotective effects of ischemic "preconditioning" are not mediated by adenosine receptors in rat hearts. Circulation 1993;87:1642-8.

14. Yellon DM, Alkhulaifi AM, Pugsley WB. Preconditioning the human myocardium. Lancet 1993;342:276-7.

15. Cohen MV, Downey JM. Preconditioning during ischemia: basic mechanisms and potential clinical applications. Cardiol Rev 1995;3:137-49.

16. Cohen MV, Liu Y, Liu GS, et al. Phospholipase D plays a role in ischemic preconditioning in rabbit heart. Circulation 1996;94:1713-8.

17. Hashimi W, Yang X-M, Lambert C, Downey JM, Cohen 
MV. Bradykinin may be the drug of choice for preconditioning the heart in the clinical setting [abstract]. Circulation 1995;92 (Suppl):I456.

18. Liu GS, TThornton J, Van Winkle DM, Stanley AWH, Olsson RA, Downey JM. Protection against infarction afforded by preconditioning is mediated by $A_{1}$ adenosine receptors in rabbit heart. Circulation 1991;84:350-6.

19. Thornton JD, Daly JF, Cohen MV, Yang X-M, Downey JM. Catecholamines can induce adenosine receptor-mediated protection of the myocardium but do not participate in ischemic preconditioning in the rabbit. Circ Res 1993;73:649-55.

20. Bankwala Z, Hale SL, Kloner RA. Alpha adrenoceptor stimulation with exogenous norepinephrine or release of endogenous norepinephrine, mimics ischemic preconditioning [abstract]. Circulation 1993;88(Suppl):I488.

21. Schott RJ, Rohmann S, Braun ER, Schaper W. Ischemic preconditioning reduces infarct size in swine myocardium. Circ Res 1990;66:1133-42.

22. Ikonomidis JS, Shirai T, Weisel RD, et al. "Ischemic" or adenosine preconditioning of human ventricular cardiomyocytes is protein kinase $\mathbf{C}$ dependent [abstract]. Circulation 1995;92(Suppl):I12.

23. Deutsch E, Berger M, Kussmaul WG, Hirshfeld JW Jr, Herrmann HC, Laskey WK. Adaptation to ischemia during percutaneous transluminal coronary angioplasty: clinical, hemodynamic, and metabolic features. Circulation 1990;82:2044-51.
24. Cribier A, Korsatz L, Koning R, et al. Improved myocardial ischemic response and enhanced collateral circulation with long repetitive coronary occlusion during angioplasty: a prospective study. J Am Coll Cardiol 1992;20:57886.

25. Kloner RA, Shook T, Przyklenk K, et al. Previous angina alters in-hospital outcome in TIMI 4: a clinical correlate to preconditioning? Circulation 1995;91:37-45.

26. Ottani F, Galvani M, Ferrini D, et al. Prodromal angina limits infarct size: a role for ischemic preconditioning. Circulation 1995;91:291-7.

27. Tsuchida A, Liu Y, Liu GS, Cohen MV, Downey JM. $\alpha_{1}$-Adrenergic agonists precondition rabbit ischemic myocardium independent of adenosine by direct activation of protein kinase C. Circ Res 1994;75:576-85.

28. Van Winkle DM, Thornton JD, Downey DM, Downey JM. The natural history of preconditioning: cardioprotection depends on duration of transient ischemia and time to subsequent ischemia. Coron Artery Dis 1991;2:613-9.

29. Kitakaze M, Hori M, Tamai J, et al. $\alpha_{1}$-Adrenoceptor activity regulates release of adenosine from the ischemic myocardium in dogs. Circ Res 1987;60:631-9.

30. Gorman MW, Ning X-H, He M-X, Portman MA, Sparks $H V$. Adenosine release and high energy phosphates in intact dog hearts during norepinephrine infusion. Circ Res 1992;70: 1146-51. 